\title{
STRATEGI PENGEMBANGAN PORTOFOLIO PRODUK INVESTASI BANK ABC
}

\section{PORTFOLIO DEVELOPMENT STARTEGIES OF INVESTMENT PRODUCTS OF BANK ABC}

\author{
Sampor Ali ${ }^{* 1}$, Lukman M. Baga ${ }^{* *}$, dan Bunasor Sanim*) \\ *) PT BNI KCP Pondok Cina \\ Jl. Margonda Raya Np 47A, Depok 16424 \\ ${ }^{* *}$ Departemen Agribisnis, Fakultas Ekonomi dan Manajemen, Institut Pertanian Bogor \\ Jl. Kamper Wing 4 Level 5 Kampus IPB, Bogor 16680 \\ ${ }^{*}$ Sekolah Bisnis, Institut Pertanian Bogor \\ Jl. Raya Pajajaran, Bogor 16151
}

\begin{abstract}
This article particularly aimed to analyze the Strengths, Weaknesses, Opportunities and Threats of the investment products. Assessing the environmental factors that affect the attractiveness of the industry and the business Strength of investment product in wealth management division in GE matrix provides recommendations of the alternative strategy for investment products in the future. The formulation of strategies product development was carried out using a portfolio analysis of Matrix General Electric (GE). The GE Matrix showed that the deposit product and retirement savings were in the first quadrant while attraction or interest in the industry was still high. Savings products were in quadrant II Planning, indicating that the company had a high business strength, but the attractiveness of the industry for these categories was in the normal position. The bancassurance products, bonds and mutual funds were in quadrant III where at this phase of the company business Strength was in the normal position, and the attractiveness of the market or industry was also in the normal position. Strategies for the development of deposits and retirement savings products included the market development and product development strategies. Savings Product Planning used penetration and product development whereas the Bancassurance products, bonds and mutual funds used market penetration strategy.
\end{abstract}

Keywords: bank, wealth management, portfolio analysis, GE matrix

\begin{abstract}
Abstrak: Penelitian bertujuan melakukan analisa kekuatan, kelemahan, peluang serta ancaman produk investasi. Mengkaji faktor lingkungan yang memengaruhi daya tarik industri dan kekuatan bisnis produk investasi di divisi wealth management dalam bentuk matrik portofolio produk, sehingga dapat memberikan rekomendasi strategi alternatif terhadap produk investasi di masa depan. Rumusan strategi pengembangan portofolio menggunakan Matriks General Electric (GE). Hasil Matriks GE menunjukkan bahwa produk deposito dan tabungan pensiun berada dalam kuadran I, yaitu daya tarik dalam industri masih tinggi. Produk Tabungan Perencanaan berada dalam kuadran II yaitu perusahaan memiliki kekuatan bisnis yang tinggi namun daya tarik industri untuk kategori-kategori tersebut pada posisi biasa. Sedangkan produk bancassurance, obligasi dan Reksadana berada pada kuadran III dimana pada fase ini kekuatan bisnis perusahaan pada posisi biasa dan daya tarik pasar atau industri juga pada posisi biasa. Perumusan strategi pengembangan untuk produk deposito dan tabungan pensiun menggunakan strategi pengembangan pasar dan strategi pengembangan produk. Produk Tabungan Perencanaan menggunakan Penetrasi dan Pengembangan produk. Produk Bancassurance, Obligasi dan Reksadana menggunakan strategi penetrasi pasar.
\end{abstract}

Kata kunci: bank, wealth management, analisis portofolio, matriks GE

${ }^{1}$ Alamat Korespondensi:

Email: sampor_ali@yahoo.com 


\section{PENDAHULUAN}

Pertumbuhan bisnis perbankan mengalamipertumbuhan yang cukup signifikan 10 tahun belakangan. Hal ini terlihat dari perkembangan dana pihak ketiga (DPK) yang dihimpun oleh bank-bank nasional terutama lima bank terbesar di Indonesia, yaitu Bank Mandiri, Bank BRI, BNI, Bank BCA dan Bank Danamon. Total dana yang dihimpun oleh perbankan dari tahun 2009-2013 tercatat mengalami kenaikan yang cukup signifikan, yaitu dari 1.913 triliun menjadi 3.575 triliun di tahun 2013 (BPS, 2014). Perkembangan total DPK tersebut diiringi dengan pertumbuhan laba perusahaan yang melaju pesat hingga puluhan triliun. Tercatat laba terbesar yang berhasil dicetak oleh Bank BRI dalam tahun 2014 adalah sebesar Rp20 triliun.

Data nasabah prioritas yang terdapat dalam beberapa bank, memperlihatkan bahwa terdapat gap yang sangat besar antara potensi yang belum tergarap dengan jumlah nasabah yang mempunyai rekening di bank. Bank-bank besar BUMN seperti Bank Mandiri mengelola total aset nasabah prioritas sebesar 137 trilun rupiah, total kelolaan aset nasabah prioritas BNI sebesar 45 triliun rupiah, BRI mengelola aset sebesar 35 triliun rupiah dan BCA sebesar 40 triliun rupiah. Peluang pangsa pasar yang belum digarap perlu dilakukan perencanaan strategik oleh Bank ABC agar dapat memenangkan persaingan, sehingga dipandang perlu dilakukan pembedahan portofolio produk investasi bank agar diketahui kekuatan dan kelemahan, serta posisi produk terhadap produk sejenis di bank lain melalui analisis portofolio.

Analisis portofolio terhadap unit bisnis membantu perusahaan untuk merencanakan strategi yang akan dilakukan pada setiap unit bisnis sesuai dengan tujuan perusahaan. Hax dan Majluf (1991) menyatakan ada beberapa teknik dalam melakukan analisis portofolio, antara lain The Boston Consulting Group Matrix, General Electric Matrix. Pearce and Robinson (2013) menambahkan selain teknik GE matriks dan BCG terdapat satu teknik lagi, yaitu Matriks Lingkungan Strategis BCG yang merupakan pengembangan dari teknik Matriks BCG. Seperti yang dikemaukan oleh Armstrong et al. (1994) Teknik portofolio ini sudah digunakan lebih dari 20 tahun dengan penjelasan bahwa teknik ini banyak memberikan panduan bagi perusahaan atas pilihan strategi yang akan diambil. Žic et al. (2009) juga berpendapat bahwa analisis portofolio memberikan kontribusi yang besar dalam mengidentifikasikan permasalahan terhadap perencanan strategi perusahaan jangka pendek dan perencanaan jangka panjang, pendapat tersebut juga diperkuat oleh penelitian McDonald dan Roberts (1992) dan Amatuli et al. (2010) tentang analisis portofolio.

Penelitian Udoh Imeh et al. (2012) menjelaskan bahwa GEMatrix,DPMMatrix,BCG Matrix danADLstrategic condition matrix adalah alat untuk memformulasikan strategi bisnis bagi perusahaan dalam melakukan perencanaan strategik dan perkembangan unit bisnis perusahaan. Hal tersebut juga dikuatkan oleh penelitian Masárová dan Krizanova (2013) yang menggunakan metode BCG dan GE Matrix dalam membedah industri konstruksi di Slovakia.

Alasan terpenting melakukan analisis portofolio produk adalah untuk memahami profil strategi produk serta mengetahui lebih dini posisi produk di pasar sehingga memudahkan perusahaan dalam memetakan sumber daya secara tepat (Žic, 2009). Penelitian yang telah dilakukan menggunakan analisis SWOT kemudian melakukan analisis portofolio, yaitu Bayu (2012) meneliti portofolio produk tabungan PT Bank Mandiri (Persero) Tbk dengan menggunakan Matrik GE. Sumarno (2011) pada PT Bank Bukopin menggunakan Matrik BCG untuk membandingkan dengan produk pesaing dan Matrik GE dan PLC Analysis atas masingmasing produk tabungan. Poniran (2013) melakukannya pada PT Gudang Garam Tbk dengan menggunakan Matrik BCG, matrik GE dan PLC analysis atas masingmasing produknya.

PT. Bank ABC (Persero)Tbk sebagai salah satu bank terbesar di Indonesia menargetkan pertumbuhan dana pihak ketiga dari bisnis wealth management sebesar 18-20\% dengan total kelolaan aset sebesar Rp48 triliun. Bank ABC mematok aset minimal untuk menjadi nasabah wealth management sebesar satu miliar rupiah. Produk yang menjadi andalan untuk menarik nasabah prioritas tersebut adalah Deposito, tabungan Pensiun, Tabungan Perencanaan, bancassurance, Obligasi dan Reksadana. Produk-produk tersebut terdiri dari produk bank dan non bank. Produk non bank terdiri dari bancassurance, reksadana dan obligasi. Penjualan produk tersebut menggunakan jasa pegawai yang sudah mempunyai sertifikasi sebagai agen penjual. Kendala dilapangan yang dihadapi oleh Bank ABC adalah, banyaknya kantor cabang yang tidak mempunyai sumberdaya yang cukup untuk kategori pegawai yang mempunyai sertifikasi. Selain itu dengan penjualan 
produk investasi non bank yang relatif baru di bank, membuat produk ini kurang diprioritaskan sebagai pilihan utama investasi sebagian nasabah. Fitur, benefit dan informasi mengenai produk investasi nonbank masih kurang dikenal oleh sebagian besar nasabah. Hal ini membuat perlu diadakannya pemetaan kekuatan dan posisi produk investasi pada Bank ABC diantara bank competitor. Hal ini disebabkan karena produkjuga dimiliki oleh bank-bank pesaing, sehingga perlu dilakukan perencanaan strategic terhadap produk investasi agar dapat merebut pasar konsumen wealth management. Berdasarkan hal tersebut, maka yang menjadi tujuan penelitian ini adalah mengkaji faktor lingkungan yang memengaruhi daya tarik industri dan kekuatan bisnis produk investasi wealth management dalam bentuk matrik portofolio produk. Di samping itu, penelitian ini juga bertujuan memberikan rekomendasi alternatif strategi produk investasi dalam strategi pengembangan produk.

Lingkup penelitian ini terbatas pada enam produk investasi Bank $\mathrm{ABC}$ yang dijual kepada nasabah wealth management, yang terdiri atas produk investasi bank dan produk investasi non bank. Produk investasi bank, yaitu deposito, tabungan pensiun, dan tabungan perencanaan. Produk investasi non bank terdiri dari bancassurance, obligasi dan reksadana.

\section{METODE PENELITIAN}

Jenis dan sumber data yang digunakan dalam penelitian ini adalah data primer dan data sekunder. Jenis data primer terdiri dari faktor daya tarik industri yang bersumber dari pihak ekternal (ahli/expert) dan penilaian faktor-faktor kekuatan bisnis perusahaan yang didapat dari sumber internal perusahaan. Jenis data sekunder yang menjelaskan tentang perkembangan produk investasi Bank ABC bersumber dari data Divisi Wealth Management dan Divisi Product Management.

Data primer diperoleh dengan langkah menentukann sampel responden menggunakan teknik purposive sampling dan kemudian dipilih judgment sampling ditambah dengan wawan cara pihak eksternal atau expert. Koresponden terdiri dari pihak internal yaitu direktur utama Bank ABC, GM Divisi Wealth Management Bank ABC, VP Divisi Product management Bank $\mathrm{ABC}$ serta dari pihak eksternal adalah Ketua Asosiasi Wealth Management Indonesia.
Data sekunder diperoleh dari data internal perusahaan seperti data SDM, keuangan serta penjualan. Data lain diperoleh dari jurnal, buku, tesis dan sumber lain yang berhubungan dengan topik penelitian.

Hasil pemilihan variabel yang relevan terhadap faktor-faktor kritis daya tarik industri dan kekuatan bisnis perusahaan kemudian dilakukan pembobotan dan pemeringkatan untuk digunakan sebagai dasar penyusunan Matrix GE. Langkah-langkah yang dilakukan dalam menganalisis GEMatrix adalah sebagai berikut: 1) menetapkan faktor-faktor relevan yang dapat memengaruhi daya tarik industri bisnis dari masingmasing produk investasi; 2) menetapkan faktor-faktor relevan yang dapat memengaruhi kekuatan bisnis dari masing-masing produk investasi. 3) untuk menentukan bobot yang paling dominan menggunakan metode pairewised comparison seperti yang dilakukan oleh Al Amin (2009), Kurniasanti et al. (2014), Prihantono (2010) dan Utari (2009); 4) menentukan rating faktorfaktor kritis setiap produk investasi dengan skala likert, seperti yang dilakukan Bayu (2012), Silitonga (2010) dan Setiadevi (2014); 5) menentukan total nilai faktorfaktor kritis dari hasil perkalian bobot dan rating; 6) memetakan posisi masing-masing produk investasi pada matriks GE.

Pada penelitian ini langkah pertama yang akan dilakukankan adalah menyebarkan kuesioner yang bertujuan untuk menentukan dan memilih variabelvariabel kekuatan bisnis oleh pihak internal yaitu Bank $\mathrm{ABC}$ dan daya tarik industri oleh pihak eksternal yaitu Ketua Asosiasi Wealth Management yang relevan untuk setiap produk.

Langkah kedua yaitu melakukan pembobotan pada masing-masing produk dengan menggunakan pairwise comparison method kemudian dilanjutkan dengan pemeringkatan menggunakan skala likert terhadap variable-variabel kekuatan bisnis dan daya tarik industri setiap produk dan selanjutnya dilakukan pemetaan posisi setiap produk kedalam Matriks GE.

Langkah ketiga adalah merumuskan strategi pengembangan atas masing-msing produk mengacu pada empat strategi pertumbuhan, yaitu strategi pertumbuhan intensif, strategi pertumbuhan integratif, strategi pertumbuhan diversifikasi dan strategi bertahan. 
HASIL

Faktor Lingkungan yang Memengaruhi Daya Tarik Industri dan Kekuatan Bisnis Produk Investasi Wealth Management dalam Bentuk Matrik Portofolio Produk

Variabel-variabel yang terpilih oleh pihak internal perusahaan yang dijadikan sebagai kekuatan bisnis perusahaan terpilih sebanyak 13 variabel, yaitu pangsa pasar, kompetensi manajemen, reputasi dan image bank, variasi dan inovasi produk, promosi, aktivitas promosi, tingkat bunga, kehandalan teknologi, jaringan distribusi, kualitas pelayanan, kemudahan transaksi, kemananan produk serta biaya administrasi.
Variable eksternal atau daya tarik industri terdiri dari pangsa pasar, pertumbuhan pasar, tingkat suku bunga, intensitas persaingan, kemajuan teknologi, sumber daya manusia, tingkat inflasi, pertumbuhan ekonomi, posisi tawar nasabah, ancaman pendatang baru, ancaman produk pengganti, margin keuntungan industri serta risiko pasar.

Variabel-variabel tersebut kemudian ditentukan bobot dan rating dari setiap faktor kritis, yang kemudian ditentukan nilai dari setiap faktor dengan mengalikan antara bobot produk dengan rating produk yang sebelumnya sudah di hitung. Nilai daya tarik industri dan kekuatan bisnis setiap produk pada Tabel 1 .

Tabel 1. Nilai daya tarik industri dan kekuatan bisnis produk investasi Bank ABC

\begin{tabular}{|c|c|c|c|c|c|c|}
\hline \multirow[t]{2}{*}{ Faktor Kritis } & Deposito & $\begin{array}{c}\text { Tabungan } \\
\text { pensiun }\end{array}$ & $\begin{array}{c}\text { Tabungan } \\
\text { bencana }\end{array}$ & Obligasi & Bancassurance & Reksadana \\
\hline & Nilai & Nilai & Nilai & Nilai & Nilai & Nilai \\
\hline \multicolumn{7}{|l|}{ Daya Tarik Industri } \\
\hline Pangsa pasar & 0,35 & 0,42 & 0,28 & 0,37 & 0,15 & 0,32 \\
\hline Pertumbuhan pasar & 0,18 & 0,45 & 0,22 & 0,26 & 0,16 & 0,26 \\
\hline Tingkat suku bunga & 0,29 & 0,28 & 0,18 & 0,23 & 0,15 & 0,24 \\
\hline Intensitas persaingan & 0,27 & 0,21 & 0,23 & 0,22 & 0,10 & 0,30 \\
\hline Kemajuan teknologi & 0,21 & 0,23 & 0,19 & 0,21 & 0,20 & 0,32 \\
\hline SDM & 0,51 & 0,31 & 0,10 & 0,21 & 0,11 & 0,11 \\
\hline Tingkat inflasi & 0,30 & 0,21 & 0,10 & 0,25 & 0,29 & 0,21 \\
\hline Pertumbuhan ekonomi & 0,13 & 0,36 & 0,26 & 0,18 & 0,16 & 0,31 \\
\hline Posisi tawar nasabah & 0,18 & 0,22 & 0,23 & 0,16 & 0,17 & 0,17 \\
\hline Ancaman pendatang baru & 0,32 & 0,23 & 0,17 & 0,17 & 0,27 & 0,12 \\
\hline Ancaman produk pengganti & 0,29 & 0,29 & 0,16 & 0,20 & 0,26 & 0,13 \\
\hline Margin keuntungan industri & 0,31 & 0,38 & 0,11 & 0,42 & 0,20 & 0,12 \\
\hline Risiko Pasar & 0,38 & 0,28 & 0,10 & 0,32 & 0,22 & 0,15 \\
\hline \multicolumn{7}{|l|}{ Kekuatan Bisnis } \\
\hline Pangsa pasar & 0,41 & 0,29 & 0,39 & 0,35 & 0,35 & 0.32 \\
\hline Pertumbuhan pasar & 0,33 & 0,34 & 0,35 & 0,39 & 0,32 & 0.31 \\
\hline Reputasi dan image bank & 0,27 & 0,28 & 0,28 & 0,37 & 0,36 & 0.27 \\
\hline Variasi dan inovasi produk & 0,40 & 0,30 & 0,35 & 0,29 & 0,34 & 0.28 \\
\hline Program promosi & 0,35 & 0,32 & 0,29 & 0,33 & 0,33 & 0.31 \\
\hline Aktivitas promosi & 0,35 & 0,32 & 0,32 & 0,29 & 0,33 & 0.33 \\
\hline Tingkat suku bunga & 0,26 & 0,23 & 0,26 & 0,22 & 0,27 & 0.22 \\
\hline kehandalan teknologi & 0,33 & 0,27 & 0,33 & 0,22 & 0,19 & 0.26 \\
\hline Jaringan distribusi & 0,32 & 0,32 & 0,24 & 0,26 & 0,26 & 0.26 \\
\hline kualitas pelayanan & 0,27 & 0,27 & 0,22 & 0,23 & 0,23 & 0.23 \\
\hline Kemudahan transaksi & 0,24 & 0,28 & 0,29 & 0,22 & 0,19 & 0.20 \\
\hline keamanan produk & 0,28 & 0,32 & 0,25 & 0,20 & 0,18 & 0.20 \\
\hline biaya administrasi & 0,27 & 0,27 & 0,29 & 0,17 & 0,16 & 0.24 \\
\hline
\end{tabular}


Hasil penelitian yang menggambarkan kekuatan bisnis dan daya tarik industri untuk setiap kategori produk pada divisi wealth management adalah sebagai berikut:

\section{Produk Deposito dan Tabungan Pensiun}

Pada produk deposito dan tabungan pensiun terdapat faktor-faktor kritis yang menjadi kekuatan perusahaan yaitu pangsa pasar, variasi dan inovasi produk, tingkat keamanan produk, jaringan distribusi yang merupakan sebaran dari kantor cabang, cabang pembantu, kantorkas dan sales point lainnya. Kekuatan faktor ini diharapkan dapat menangkap peluang pasar yang tersedia sehingga pertumbuhan portofolio produk investasi berupa deposito dan tabungan pensiun semakin besar, terutama produk tabungan pensiun yang merupakan product leader dalam industri perbankan serta produk deposito yang memang dipilih nasabah karena tingkat risikonya sangat rendah dibandingkan dengan produk investasi lainnya.

Perusahaan harus memberikan perhatian kepada tingkat layanan yang masih kurang, serta tingkat suku bunga (Setiawan, 2012). Tingkat suku bunga terancam dengan tingginya nilai inflasi serta masih kalahnya tingkat suku bunga bank pesaing, harus disikapi dengan menonjolkan kelebihan dari fitur produk lainnya seperti pelayanan yang lebih personal, gimmick langsung disetiap pembukaan rekening ataupun pemberian cashback. Banyaknya produk sejenis mengakibatkan daya tawar nasabah menjadi ancaman utama bagi keberlangsungan produk deposito dan tabungan pensiun. Kuatnya posisi tawar nasabah juga mengakibatkan permintaan bunga yang tinggi serta biaya administrasi yang rendah serta tuntutan layanan yang lebih baik (Yunita, 2001). Diharapkan dengan kekuatan di jaringan distribusi yang kuat Bank $\mathrm{ABC}$ dapat memperbaiki kualitas layanan, baik secara SDM, teknologi dan birokrasi.

\section{Produk Tabungan Perencanaan}

Faktor kritis kekuatan Perusahaan adalah pangsa pasar, kompetensi manajemen serta inovasi dan variasi produk. Sedangkan peluang yang ada dalam industri ini adalah masih rendahnya intensitas persaingan dalam pemasaran produk ini sehingga memberikan ruang gerak yang lebih besar bagi Bank $A B C$ untuk memanfaat peluang ini. Selain itu pangsa pasar yang tumbuh embuat peluang pertumbuhan penjualan semakin besar. Pertumbuhan pangsa pasar didasari atas pertumbuhan ekonomi yang tumbuh positif dan tingkat pendapatan masyarakat yang terus meningkat. Faktor kritis perusahaan yang menjadi kelemahan bisnis perusahaan dalam memanfaatkan peluang yang ada yaitu masih rendahnya tingkat layanan yang dirasakan oleh nasabah, kemudian tingkat suku bunga produk yang masih rendah. Tingkat risiko pasar dan tingkat inflasi adalah ancaman bagi produk Tabungan Perencanaan. Hal tersebut didasarkan atas tingkat suku bunga yang didapat dari tabungan perencaaan masih dapat tergerus oleh tingkat inflasi.

\section{Produk Bancassurance, Obligasi, dan Reksadana}

Kekuatan perusahaan pada tiga produk investasi ini adalah, reputasi bank, inovasi, promosi, pangsa pasar. Faktor-faktor kritis yang menjadi kekuatan bisnis perusahaan ini diharapkan dapat menangkap peluang dalam segmentasi pasar yang baru, ancaman produk pengganti, ancaman pendatang baru, dimana masih belum banyak bank yang secara serius menggarap produk investasi nonbank tersebut. Faktor-faktor kritis yang menjadi kelemahan perusahaan dalam memanfaatkan peluang adalah berupa kemudahan transaksi, keamanan produk serta layanan. Intensitas persaingan, sumberdaya manusia, ancaman pendatang baru serta risiko pasar adalah ancaman serius bagi produk investasi ini. Untuk menunjukkan posisi setiap kategori dalam matriks GE (Gambar 2).

Dari Gambar 2 terlihat bahwa produk deposito dan tabungan pension berada dalam quadran daya tarik industri yang tinggi dan kekuatan bisnis yang kuat atau dalam fase investasi dan pertumbuhan. Produk Tabungan perencanaan dalam quadran tumbuh selektif, dimana daya tarik industri dalam tingkat tinggi akan tetapi kekuatan bisnis perusahaan dalam fase biasa. Produk bancassurance, reksadana dan obligasi berada dalam quadran selektif dimana daya tarik industri dalam tahap biasa dan kekuatan bisnis dalam tahap sedang.

\section{Rekomendasi Alternatif Strategi Produk Investasi Dalam Strategi Pengembangan Produk}

\section{Strategi Produk Tabungan Pensiun dan Deposito}

Dalam Matriks GE kategori-kategori ini berada pada kuadran I yaitu Investasi dan Tumbuh. Penjualan pada fase ini lebih stabil petumbuhannya dibanding tahap sebelumnya dan lebih banyak tantangan bagi perusahaan karena makin banyak konsumen yang beralih ke produk lain (Kotler dan Keller, 2009). 
Oleh karena itu fokus perusahaan memaksimalkan laba sekaligus mempertahankan pangsa pasar (Hubeis dan Najib, 2009) dengan melakukan strategi pengembangan produk dengan cara memperbanyak program promosi penjualan seperti pemberian hadiah langsung, cashback, serta pemberian voucher belanja kepada nasabah. Melakukan sosialisasi tentang manfaat tabungan perencanaan kepada calon nasabah, pemberian special rate kepada nasabah potensial secara bisnis serta memaksimalkan peran sales dan pegawai dalam penjualan produk. Selanjutnya, melakukan strategi pengembangan pasar dengan memperluas jangkauan produk ke segmen masyarakat yang lebih besar. Pembukaan rekening secara online melalui channel internet banking merupakan salah satu cara agar masyarakat yang mempunyai tingkat mobilisasi tinggi dapat menggunakan fitur tersebut sehingga pembukaan rekening yang mengharuskan nasabah datang ke bank dapat diatasi. Selain itu dengan adanya kemudahan pembukaan rekening dengan cara elektronik, dapat mengakomodir segmen nasabah yang selama ini belum tertampung di saluran distribusi yang sudah ada hal ini juga dilakukan oleh Setiawan (2012) pada penelitiannya di Bank Mandiri.

\section{Strategi Produk Tabungan Perencanaan}

Produk tabungan Perencanaan berada pada kuadran II dalam matriks GE, yaitu tumbuh selektif. Pada fase ini Kotler (2009) mengemukakan bahwa pada fase selektif perusahaan menggunakan beberapa strategi untuk mengelola produk agar menghasilkan pendapatan bagi perusahaan serta mempertahankan pertumbuhan pasar selama mungkin dengan cara meningkatkan kualitas produk, hal ini juga dilakukan pada Setiawan (2012), Yunita (2001) dan Iksan (2006). Selain itu perusahaan dapat memasuki segmen baru dan meningkatkan saluran distribusi, menurunkan harga untuk menarik konsumen yang sensitif dengan harga. Strategi yang dapat yang dilakukan Bank $\mathrm{ABC}$ adalah melakukan strategi penetrasi pasar yaitu dengan menetapkan program promosi berupa pemberian hadiah langsung, gimmick dan juga cash back. Selanjutnya, strategi pengembangan atau perluasan produk layanan, yaitu dengan mempermudah akses nasabah ke investasi mereka dengan layanan e-banking, kemudahan pembukaan rekening, jangka waktu pencairan saldo tabungan yang lebih cepat dan fleksibel. Di samping itu, strategi pengembangan pasar yaitu memperluas area baru dengan melakukan kerja sama dengan institusi lain atau strategic partnership dengan perusahaan pemerintah, perguruan tinggi, pabrik-pabrik yang mempunyai banyak karyawan (payroll).

Strategi Produk Bancassurance, Obligasi dan Reksadana

Produk Investasi berupa Bancassurance, obligasi dan Reksadana berada pada kuadran III, yaitu tumbuh selektif Bank ABC berorientasi untuk memaksimalkan laba sambil mempertahankan pangsa pasar dengan merumuskan strategi intensif (Hubeis dan Najib, 2009) (Setiawan, 2012) diantaranya: Strategi penetrasi pasar. meningkatkan strategi promosi Bank $\mathrm{ABC}$ agar masyarakat luas dapat mengenal produk dan manfaatnya sehingga produk ini menjadi pilihan masyarakat untuk menginvestasikan aset mereka dan dapat dijadikan andalan pendapatan bagi Bank $\mathrm{ABC}$ pada masa datang. Selanjutnya, strategi pengembangan produk. Bank $\mathrm{ABC}$ dengan cara memperbaharui fitur produk agar lebih familiar dan dikenal oleh calon nasabah.

Industry Attractiveness

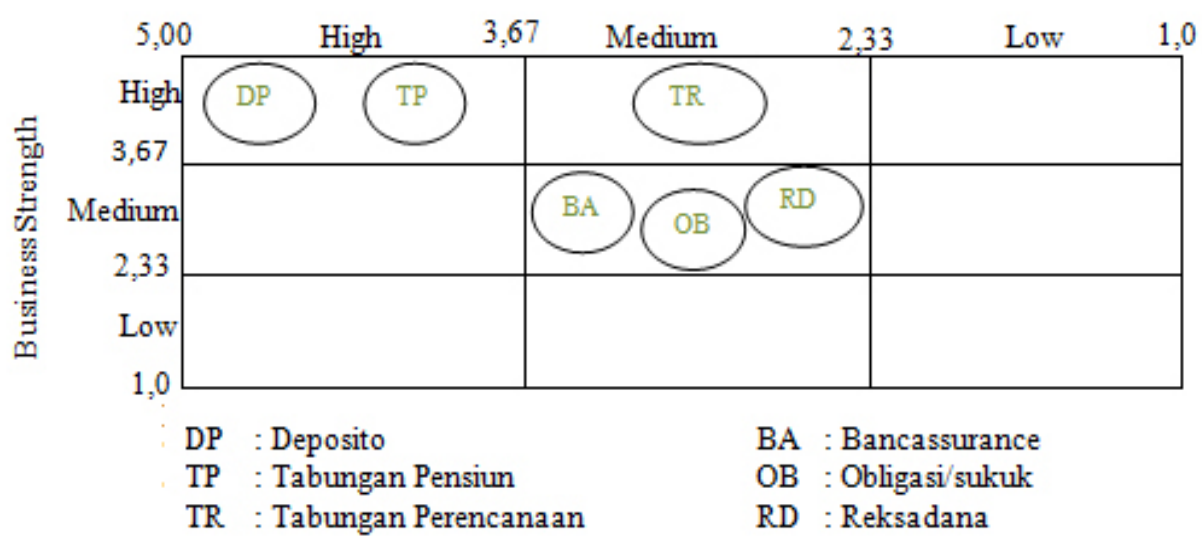

Gambar 2. Pemetaan tiap kategori pada Matriks GE 


\section{Implikasi manajerial}

Implikasi manajerial dari penelitian ini adalah Menentukan strategi penetrasi pasar untuk produk deposito dan tabungan pensiun. Perusahaan membuat program promosi penjualan seperti pemberian hadiah langsung, cashback, serta pemberian voucher belanja kepada nasabah. Melakukan sosialisasi tentang manfaat tabungan perencanaan kepada calon nasabah, pemberian special rate kepada nasabah potensial secara bisnis serta memaksimalkan peran sales dan pegawai dalam penjualan produk. Selain itu perusahaan juga perlu memperluas jangkauan produk ke segmen masyarakat yang lebih besar. Layanan kemudahan pembukaan rekening dengan cara elektronik, dapat mengakomodir segmen nasabah yang selama ini belum tergarap secara serius di saluran distribusi yang sudah ada.

Penetapan starategi produk Tabungan Perencanaan berupa strategi penetrasi pasar, kemudian dilanjutkan dengan strategi pengembangan atau perluasan produk, layanan yaitu dengan mempermudah akses nasabah ke investasi mereka dengan layanan e-banking, kemudahan pembukaan rekening, jangka waktu pencairan saldo tabungan yang lebih cepat dan fleksibel, dan yang terakhir adalah pengembangan pasar yaitu memperluas area baru dengan melakukan kerja sama dengan institusi lain atau strategic partnership dengan perusahaan pemerintah, perguruan tinggi, pabrik-pabrik yang mempunyai banyak karyawan (payroll). Untuk Produk investasi non bank, yaitu bancassurance, obligasi dan reksadana ditetapkan aplikasi strategi penetrasi pasar. meningkatkan strategi promosi bank $\mathrm{ABC}$ agar masyarakat luas dapat mengenal produk dan manfaatnya sehingga produk ini menjadi pilihan masyarakat untuk menginvestasikan dan melipatgandakan aset mereka dan dapat dijadikan andalan pendapatan bagi Bank $\mathrm{ABC}$ pada masa datang. Kedua adalah strategi pengembangan produk. Bank $\mathrm{ABC}$ dapat memperbaharui fitur produk agar lebih familiar dengan tingkat pemahaman masyarakat, kemudahan akses informasi produk serta teknologi yang mensupport transaksi secara fleksibel dan mudah.

\section{KESIMPULAN DAN SARAN}

\section{Kesimpulan}

Produk Deposito dan tabungan pensiun berada dalam tahap kuat, perusahaan dalam hal ini divisi wealth management dapat berkonsentrasi kepada kekuatan bisnis agar tercipta pertumbuhan maksimum dan agar produk tersebut terus berlangsung. Tabungan Perencanaan berada dalam tahap tumbuh selektif sehingga perusahaan dapat mempertahankan program yang ada dan berkonsentrasi terhadap segmen yang dituju. Produk investasi non bank, yaitu bancassurance, obligasi dan reksadana berada dalam kuadran selektif. Posisi tersebut disebabkan oleh kurangnya promosi dan sumber daya manusia (officer) yang memadai.

Rekomendasi alternatif strategi produk deposito dan tabungan pensiun adalah perlu dilakukan pengembangan produk dan pengembangan pasar berupa penentuan segmentasi baru. Produk Tabungan perencanaan menggunakan strategi pengembangan pasar dan diversifikasi konsentrik. Dalam memasarkan produk investasi yang berada dalam quadran selektif, perusahaan dapat meningkatkan kegiatan dan intensitas promosi produk investasi non bank melalui seluruh saluran distribusinya (kantor cabang, kantor cabang pembantu dan kantor kas). Selain itu faktor Potensi bisnis berupa terus bertambahnya jumlah nasabah yang ber-asset besar membuka peluang bagi Bank $\mathrm{ABC}$ untuk menggunakan kekuatan perusahaan untuk merebut pasar serta memperbaiki kelemahan dan kekurangan yang ada.

\section{Saran}

Menghadapi kebutuhan nasabah yang lebih kompleks serta intensitas persaingan pada tahun mendatang, Bank $\mathrm{ABC}$ harus mengintensifkan bauran pemasaran, seperti menambah fitur produk investasi, kemudahan akses nasabah terhadap hasil investasi dan informasi produk, menambah officer yang bersertifikasi dengan tujuan agar dapat memasarkan lebih agresif produk investasi kepada nasabah serta meningkatkan aktivitas promosi below the line dan above the line agar produk dikenal oleh masyarakat.

\section{DAFTAR PUSTAKA}

Al Amin, M Taufiq. 2009. Analisis strategi portofolio produk tabungan di PT. Bank Muamalat Indonesia (BMI)[tesis]. Bogor: Institut Pertanian Bogor.

Amatuli C, Caputo T, Guido G. 2010. Strategic analysis through the general electric/mckinsey matrix. an application to The Italian Fashion 
Industry. International Journal of Business and Management 6(5):61-74.

Armstrong JS, Brodie RJ. 1994. Effects of portfolio planning methods on decision making: experimental result. International Journal of Research in Marketing 11(1): 73-84. https://doi. org/10.1016/0167-8116(94)90035-3.

Hax AC, Majluf NS. 1991. The strategy concept and process: a pragmatic approach. Englewood. New Jersey: Prentice Hall

Hubeis M, Najib M. 2008. Manajemen Strategik dalam Pengembangan Daya Saing Organisasi. Jakarta: PT. Elex Media Komputindo.

Iksan. 2006. Analisis portofolio dengan matrik gemckinsey di perusahaan plastik "keris". Journal of industrial Engineering and management 3(2):106-121.

Kotler P, Keller KL. 2009. Manajemen Pemasaran. Bob Sabran, penerjemah. Jakarta: Penerbit Erlangga.

Kurniasanti S, Sumarwan U, Kurniawan B. 2014. Analisis dan model strategi peningkatan daya saing produk edamame beku. Jurnal Manajemen \& Agribisnis 11(3):154-163.

McDonald G, Roberts C. 1992. What you always wanted to know about marketing strategy...but were too confused to ask. Management Decision 30(7). https://doi.org/10.1108/00251749210017335.

Pearce II JA. Robinson RB. 2014. Manajemen Strategis; Formulasi. Implementasi dan Pengendalian. Nia Pramita Sari, penerjemah. Jakarta: Penerbit Salemba Empat.

Poniran. 2013. Strategi the boston consulting group untuk memastikan kesinambungan produk PT Gudang Garam Tbk. Kediri. Wacana 16(1):114.
Porter ME. 1994. Keunggulan Bersaing. Menciptakan dan Mempertahankan Kinerja Unggul. Sigit Suryanto. Penerjemah. Tangerang: Karisma Publishing Group.

Prihantono TJ. 2010. Strategi pengembangan bisnis mikro PT. Bank Bukopin Tbk. [tesis]. Bogor: Institut Pertanian Bogor

Setiadevi S, Fahmi I, Wibisono Y. 2014. Kualitas jasa unit pelaksana teknis pengujian sertifikasi mutu barang-lembaga tembakau jember. Jurnal Manajemen \& Agribisnis 11(3):144-153

Bayu TA. 2012. Analisis portofolio produk tabungan dan strategi pengembangannya (Studi Kasus pada PT Bank mandiri (Persero) Tbk Area Banjarmasin) [tesis]. Bogor: Institut Pertanian Bogor

Silitonga P. 2010. Analisis strategi portofolio komoditi PT. Perkebunan Nusantara III [tesis]. Bogor. Institut Pertanian Bogor

Sumarno. 2011. Analisis portofolio produk tabungan dan strategi pengembangan (studi kasus pada PT Bank Bukopin. Tbk) [tesis]. Bogor: Institut Pertanian Bogor

Udo-Imeh TP, Edet EW, Anani BR. 2012 Portfolio analysis models: a review. European Journal of Business and Management 4(18): 101-120.

Utari BW. 2009. Strategi portofolio produk tabungan PT. Bank Perkreditan Rakyat (BPR) Cicurug Bumi Asih [tesis]. Bogor. Institut Pertanian Bogor

Yunita M. 2001. Kajian Portofolio Produk PT. Bank Ekspor Indonesia (Persero). Jurnal Ilmiah Kesatuan 1(3):1-8.

Žic S, Hadzic H, Ikonic M. 2009. Portfolio analysisa useful management tool. Technical Gazette 16(4): 101-105. 